\title{
The Effect of Dry Unit Weight in Hydrodynamic Dispersion of Clayey Soils
}

\author{
Baris Mahmutluoglu ${ }^{1}$, Baki Bagriacik ${ }^{2}$ \\ ${ }^{1}$ Mersin University, Construction Technology Department, Mersin 33250,Turkey \\ ${ }^{2}$ Cukurova University, Civil Engineering Department, Adana01330, Turkey
}

\begin{abstract}
In this study, hydrodynamic dispersion is explained which is the combined effect of grain diffusion and dispersion of a soil. Dry unit weight of a soil is shown to be the most effective parameter in hydrodynamic dispersion. The results obtained by traditional consolidation tests are compared to the theoretically obtained counterparts. All of the aforementioned theoretical values are derived from the theory of hydrodynamic dispersion. Additionally, by considering the hydrodynamic dispersion of a soil during consolidation, time rates of pore water, settlements and compression of soil skeleton can also be considered in terms of hydrodynamic dispersion and so the viscous properties of soils are able to be investigated as well. It can also be pointed out that the obtained data can especially support the studies about slope stability problems of soils.
\end{abstract}

Keywords:hydrodynamic dispersion, soil skeleton, time rates of settlement, dry unit weight, pore water, grain diffusion, dispersion

\section{Introduction}

Hydrodynamic dispersion is a phenomenon in which soil particles form a more disperse structure by means of orientation and soil grains diffuse because of very low time rates of settlement[1].

This phenomenon takes place in micro pores and at the outside of a solid-liquid intersection as a result of low time rates of pore water [2]. Variations in time rates of settlement are in a correlation with the changes in pore water pressures [3].

\section{Material and Methodology}

Soil samples which were taken from Mersin City in Turkey were used to perform a series of traditional consolidation tests. Since dry unit weight is the most effective parameter in hydrodynamic dispersion, soil samples with different initial and final effective stress variation ratios are presented in this study.

Results of these experiments are compared to theoretical values and the effect of dry unit weight in a consolidation is expressed [4].

The phenomenon was studied statistically at first and by performing a series of regression analyses, the most compatible equations were constructed.

Consequently, Equation 1 was given as the dispersion differential equation in terms of dry unit weight [2], [4]:

$$
\frac{\partial \gamma_{k}}{\partial t}=v_{z} \frac{\partial \gamma_{k}}{\partial z}+D_{s} \frac{\partial^{2} \gamma_{k}}{\partial z^{2}}
$$

where, $\gamma_{k}$ is dry unit weight, $v_{z}$ is time rate of settlement, $D_{s}$ is diffusivity coefficient. Coordinate $\mathrm{z}$ and time $\mathrm{t}$ are the independent variables in Equation 1.

\section{Results and Tables}

Plasticity indices, dry unit weight variation ratios before and after a consolidation test, pre-consolidation pressures and over consolidation ratios of the two kind of clayey soil samples which were used in the performed tests are given below:

$$
\begin{aligned}
& \text { Soil Type } 1 \Rightarrow I_{D}=\% 13 ; \Delta \gamma_{k}=\% 10.98 ; \sigma_{c}=2.3 \mathrm{~kg} / \mathrm{cm}^{2} ; O C R=4.8 \\
& \text { Soil Type } 2 \Rightarrow I_{p}=\% 37 ; \Delta \gamma_{k}=\% 7.78 ; \sigma_{c}=2.2 \mathrm{~kg} / \mathrm{cm}^{2} ; O C R=4.7
\end{aligned}
$$

Results of the performed consolidation tests and diffusive and dispersive parametersof the Soil Type 1 samples can be seen in Table 1 and Table 2, respectively.

Results of the performed consolidation tests and diffusive and dispersive parameters of the Soil Type 2 samples can be seen in Table 3 and Table 4, respectively.

\begin{tabular}{|c|c|c|c|c|c|c|}
\hline$\underset{\left(\mathrm{kg} / \mathrm{cm}^{2}\right)}{p}$ & $\begin{array}{c}\text { Samp. } \\
\text { Height } \\
\underset{(\mathrm{mm})}{H}\end{array}$ & $\begin{array}{c}\text { e } \\
(\%)\end{array}$ & 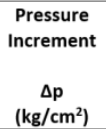 & $\begin{array}{c}\text { Dry Unit } \\
\text { Weight } \\
\\
\gamma_{\mathrm{k}} \\
\left(\mathrm{gr} / \mathrm{cm}^{3}\right)\end{array}$ & $\begin{array}{c}\text { Coeff. Of } \\
\text { Volume } \\
\text { Comp. } \\
\mathrm{m}_{\mathrm{v}} \\
\left(\mathrm{cm}^{2} / \mathrm{kg}\right)\end{array}$ & $\begin{array}{c}\text { Efective } \\
\text { Stress } \\
\text { Increment } \\
\sigma^{\prime} \\
\left(\mathrm{kg} / \mathrm{cm}^{2}\right)\end{array}$ \\
\hline 0.00 & 20.00 & 0.667 & - & 1.484 & - & - \\
\hline 0.51 & 19.62 & 0.635 & 0.51 & 1.513 & 0.0373 & 0.52 \\
\hline 1.02 & 19.33 & 0.611 & 0.51 & 1.536 & 0.0290 & 0.52 \\
\hline 2.04 & 18.95 & 0.579 & 1.02 & 1.567 & 0.0193 & 1.04 \\
\hline 4.08 & 18.39 & 0.533 & 2.04 & 1.614 & 0.0145 & 2.04 \\
\hline 8.15 & 17.67 & 0.473 & 4.08 & 1.680 & 0.0096 & 4.17 \\
\hline 4.08 & 17.80 & 0.483 & 4.08 & 1.668 & 0.0017 & 4.22 \\
\hline 1.02 & 18.02 & 0.502 & 3.06 & 1.647 & 0.0041 & 3.09 \\
\hline
\end{tabular}

Table 1: Effective stress variations relative to dry unit weights for the soil type 1 sample 


\section{International Journal of Science and Research (IJSR) \\ ISSN (Online): 2319-7064 \\ Index Copernicus Value (2015): 78.96 | Impact Factor (2015): 6.391}

Table 2: Dispersion results of the soil type 1 sample

\begin{tabular}{|c|c|c|c|c|c|c|}
\hline $\begin{array}{c}\text { Total } \\
\text { Press. } \\
\begin{array}{c}\mathbf{p} \\
\left(\mathrm{kg} / \mathrm{cm}^{2}\right)\end{array}\end{array}$ & $\begin{array}{c}\text { Dry } \\
\text { Unit Weight } \\
\gamma_{k} \\
\left(\mathrm{gr} / \mathrm{cm}^{3}\right)\end{array}$ & $\begin{array}{l}\text { Dif. Coeff. } \\
\qquad \begin{array}{l}D_{5} \times 10^{-5} \\
\left(\mathrm{~cm}^{2} / \mathrm{dk}\right)\end{array}\end{array}$ & $\begin{array}{l}\text { Disp. } \\
\text { Vrb. } \\
x \\
x\end{array}$ & $\begin{array}{c}\text { Disp. } \\
\text { Flux } \\
\mathrm{J}_{\mathrm{s}} \\
\left(\mathrm{gr} / \mathrm{cm}^{2} \mathrm{dk}\right)\end{array}$ & $\begin{array}{c}\text { Dispers. } \\
\text { Soil } \\
\text { Amount } \\
\Delta \mathrm{W}_{\mathrm{s}} \\
\text { (gr) }\end{array}$ & $\begin{array}{c}\text { Total Comp. } \\
\text { Soil } \\
\Delta \mathrm{W}_{\mathrm{t}} \\
(\mathrm{gr})\end{array}$ \\
\hline 0.00 & 1.484 & - & - & - & - & - \\
\hline 0.51 & 1.513 & 1.282 & 7.220 & $3.54 \times 10^{-29}$ & $1.0 \times 10^{-24}$ & 0.0216 \\
\hline 1.02 & 1.536 & 2.210 & 5.418 & $6.48 \times 10^{-19}$ & $1.8 \times 10^{-14}$ & 0.0684 \\
\hline 2.04 & 1.567 & 3.362 & 4.306 & $6.34 \times 10^{-14}$ & $1.8 \times 10^{-9}$ & 0.1711 \\
\hline 4.08 & 1.614 & 4.928 & 3.452 & $9.06 \times 10^{-11}$ & $2.6 \times 10^{-6}$ & 0.4109 \\
\hline 8.15 & 1.680 & 6.714 & 2.841 & $7.46 \times 10^{-9}$ & $2.1 \times 10^{-4}$ & 0.8965 \\
\hline 4.08 & 1.668 & 6.410 & 2.929 & $4.12 \times 10^{-9}$ & $1.2 \times 10^{-4}$ & 0.7946 \\
\hline 1.02 & 1.647 & 5.877 & 3.097 & $1.27 \times 10^{-9}$ & $0.4 \times 10^{-4}$ & 0.6335 \\
\hline
\end{tabular}

Note: Since consolidation is concluded at the end of each pressure increment, time rate of settlement $\mathrm{v}_{\mathrm{z}}$ was taken as $\mathrm{v}_{\mathrm{z}}=0$.

Table 3: Effective stress variations relative to dry unit weights for the soil type 2 sample

\begin{tabular}{|c|c|c|c|c|c|c|}
\hline $\begin{array}{c}p \\
\left(\mathrm{~kg} / \mathrm{cm}^{2}\right)\end{array}$ & $\begin{array}{c}\text { Samp. } \\
\text { Height } \\
\underset{(\mathrm{mm})}{\mathrm{H}}\end{array}$ & $\begin{array}{c}\text { Void Ratio } \\
\text { e } \\
(\%)\end{array}$ & $\begin{array}{c}\text { Pressure } \\
\text { Increment } \\
\begin{array}{c}\Delta \mathrm{p} \\
\left(\mathrm{kg} / \mathrm{cm}^{2}\right)\end{array}\end{array}$ & $\begin{array}{c}\text { Dry Unit } \\
\text { Weight } \\
\\
\gamma_{k} \\
\left(\mathrm{gr} / \mathrm{cm}^{3}\right)\end{array}$ & $\begin{array}{c}\text { Coeff. Of } \\
\text { Volume } \\
\text { Comp. } \\
\mathrm{m}_{\mathrm{v}} \\
\left(\mathrm{cm}^{2} / \mathrm{kg}\right)\end{array}$ & $\begin{array}{c}\text { Efective } \\
\text { Stress } \\
\text { Increment } \\
\sigma^{\prime} \\
\left(\mathrm{kg} / \mathrm{cm}^{2}\right)\end{array}$ \\
\hline 0.00 & 20.00 & 0.429 & - & 1.710 & - & - \\
\hline 0.51 & 19.85 & 0.418 & 0.51 & 1.724 & 0.0146 & 0.56 \\
\hline 1.02 & 19.62 & 0.401 & 0.51 & 1.744 & 0.0228 & 0.51 \\
\hline 2.04 & 19.24 & 0.374 & 1.02 & 1.779 & 0.0190 & 1.05 \\
\hline 4.08 & 18.71 & 0.336 & 2.04 & 1.829 & 0.0136 & 2.04 \\
\hline 8.15 & 18.00 & 0.286 & 4.08 & 1.901 & 0.0093 & 4.15 \\
\hline 4.08 & 18.13 & 0.295 & 4.08 & 1.887 & 0.0017 & 4.35 \\
\hline 1.02 & 18.57 & 0.326 & 3.06 & 1.843 & 0.0080 & 2.95 \\
\hline
\end{tabular}

Table 4: Dispersion results of the soil type 2 sample

\begin{tabular}{|c|c|c|c|c|c|c|}
\hline $\begin{array}{c}\text { Total } \\
\text { Press. } \\
\\
p \\
\left(\mathrm{~kg} / \mathrm{cm}^{2}\right)\end{array}$ & $\begin{array}{c}\text { Dry } \\
\text { Unit Weight } \\
\gamma_{k} \\
\left(\mathrm{gr} / \mathrm{cm}^{3}\right)\end{array}$ & $\begin{array}{l}\text { Dif. Coeff. } \\
\mathrm{D}_{5} \times 10^{-5} \\
\left(\mathrm{~cm}^{2} / \mathrm{dk}\right)\end{array}$ & $\begin{array}{l}\text { Disp. } \\
\text { Vrb. } \\
\\
\\
\mathrm{x} \\
-\end{array}$ & $\begin{array}{c}\text { Disp. } \\
\text { Flux } \\
J_{s} \\
\left(\mathrm{gr} / \mathrm{cm}^{2} \mathrm{dk}\right)\end{array}$ & $\begin{array}{c}\text { Dispersive } \\
\text { Soil } \\
\text { Amount } \\
\\
\Delta \mathrm{W}_{\mathrm{s}} \\
(\mathrm{gr})\end{array}$ & $\begin{array}{c}\text { Total } \\
\text { Compacted } \\
\text { Soil } \\
\Delta \mathrm{W}_{\mathrm{t}} \\
(\mathrm{gr})\end{array}$ \\
\hline 0.00 & 1.710 & - & - & - & - & - \\
\hline 0.51 & 1.724 & 0.515 & 11.525 & $9.75 \times 10^{-65}$ & $2.8 \times 10^{-60}$ & 0.0041 \\
\hline 1.02 & 1.744 & 1.282 & 7.220 & $4.16 \times 10^{-29}$ & $1.2 \times 10^{-24}$ & 0.0254 \\
\hline 2.04 & 1.779 & 2.490 & 5.080 & $3.17 \times 10^{-17}$ & $9.0 \times 10^{-13}$ & 0.1029 \\
\hline 4.08 & 1.829 & 4.052 & 3.873 & $3.44 \times 10^{-12}$ & $9.7 \times 10^{-8}$ & 0.3013 \\
\hline 8.15 & 1.901 & 5.927 & 3.081 & $1.65 \times 10^{-9}$ & $4.7 \times 10^{-5}$ & 0.7499 \\
\hline 4.08 & 1.887 & 5.602 & 3.192 & $0.74 \times 10^{-9}$ & $2.1 \times 10^{-5}$ & 0.6497 \\
\hline 1.02 & 1.843 & 4.441 & 3.672 & $0.02 \times 10^{-9}$ & $0.6 \times 10^{-6}$ & 0.3733 \\
\hline
\end{tabular}

Note: Since consolidation is concluded at the end of each pressure increment, time rate of settlement $\mathrm{v}_{\mathrm{z}}$ was taken as $\mathrm{v}_{\mathrm{Z}}=0$.

Correlations between experimental and theoretical effective stress variations are given in Figure 1 and Figure 2 for the Soil Type 1 and Soil Type 2 samples, respectively.

The aforementioned theoretical values were obtained by using Equation 2 given below which was derived from the solutions of the differential equation given as Equation 1 [2], [4].

$$
\sigma^{\prime}=\frac{1}{m_{v}} \ln \frac{\gamma_{k 2}}{\gamma_{k 1}}
$$

where, $\mathrm{m}_{\mathrm{v}}$ is the coefficient of volume compressibility, $\gamma_{\mathrm{k} 1}$ and $\gamma_{\mathrm{k} 2}$ are the initial and final dry unit weights, respectively.

It is clear from the correlations in Figure 1 and Figure 2 that theoretically obtained values are very close to the experimental counterparts.

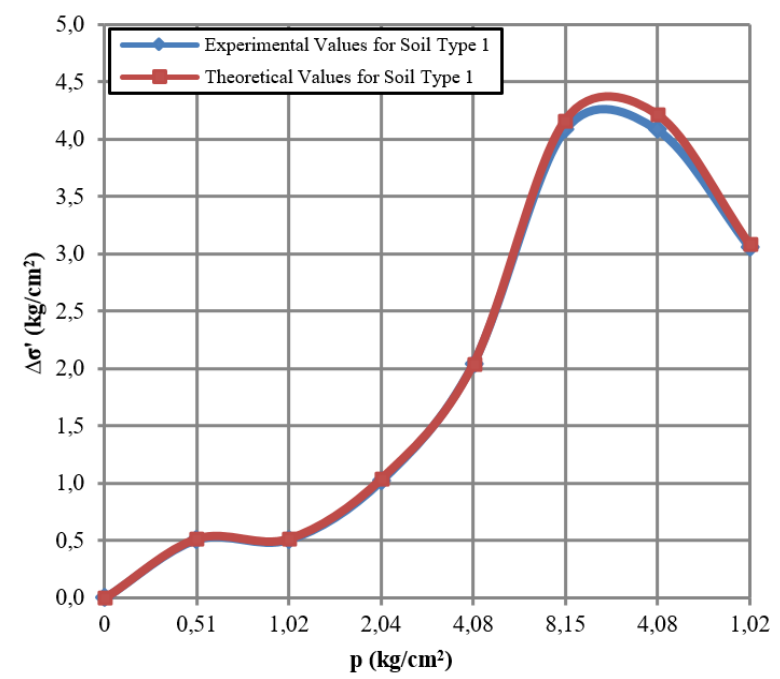

Figure 1: Correlation of theoretical $\left(\Delta \sigma^{\prime}\right)$ and experimental (p) effective stress increments for the soil type 1 sample

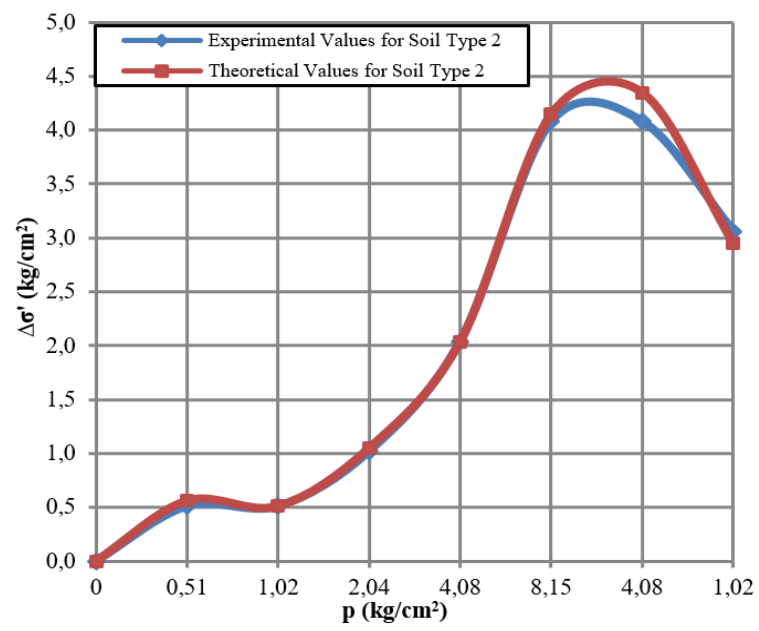

Figure 2: Correlation of theoretical $\left(\Delta \sigma^{\prime}\right)$ and experimental (p) effective stress increments for the soil type 2 sample

The comparison between diffusivity coefficients $\left(D_{s}\right)$ of the Soil Type 1 and Soil Type 2 samples are seen in Figure 3 below.

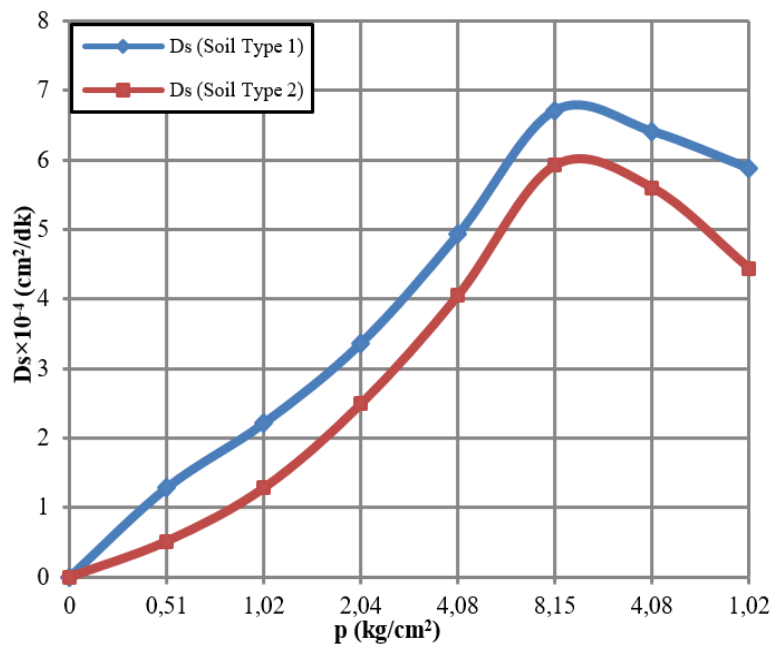

Figure 3: Correlation of diffusivity coefficients for the soil type 1 and soil type 2 samples

As a result of a higher ratio of dry unit weight variation of the Soil Type 1 sample throughout the performed tests,

\section{Volume 6 Issue 7, July 2017 www.ijsr.net}




\section{International Journal of Science and Research (IJSR) \\ ISSN (Online): 2319-7064 \\ Index Copernicus Value (2015): 78.96 | Impact Factor (2015): 6.391}

diffusivity coefficients for the Soil Type 1 samples are found to be higher than that for the Soil Type 2 samples.

The obtained values for diffusivity coefficient were obtained by using Equation 3 which was derived from the solutions of the differential equation given as Equation 1 [4].

$$
D_{s}=\frac{z^{2}}{4 t} \ln \frac{z_{i}}{z}
$$

where, $\mathrm{z}_{\mathrm{i}} \mathrm{ve} \mathrm{z}$ are the initial and any sample heights, respectively, $\mathrm{z}^{2} / 4$ is the squared power of the drainage path $\mathrm{z} / 2$ and $\mathrm{t}$ is time [4].

The values for flux $\left(\mathrm{J}_{\mathrm{s}}\right)$ and dispersive variable $(\mathrm{x})$ were found by using Equation 4.a and Equation 4.b, respectivelywhich were also derived from the solutions of the differential equation given as Equation 1, as well[4]:

$$
\begin{gathered}
J_{s}=\sqrt{\frac{D_{s}}{\pi t}} \cdot\left(\gamma_{k f}-\gamma_{k i}\right) e^{-x^{2}} \\
x=\frac{z+v_{z} t}{2 \sqrt{D_{s} t}}
\end{gathered}
$$

where, $D_{\mathrm{s}}$ is the diffusivity coefficient, $\gamma_{\mathrm{ki}}$ and $\gamma_{\mathrm{kf}}$ are the initial and final values for dry unit weights, respectively, $\mathrm{v}_{\mathrm{z}}$ is the time rate of settlement, $\mathrm{z}$ is the sample height at any instant and $t$ is time[4].

The values for the amount of soil filling into macro pores and diffusing inside the soil matrixwere found by Equation 5 below[4]:

$$
\Delta W_{s}=J_{s} A \Delta t
$$

where, $\mathrm{J}_{\mathrm{s}}$ is flux, $\mathrm{A}$ is the cross sectional area and $\mathrm{t}$ is time[4]. The correlation between total compacted soil amounts $\left(\Delta \mathrm{W}_{t}\right)$ of the Soil Type 1and Soil Type 2 samples can be seenin Figure 4 below.

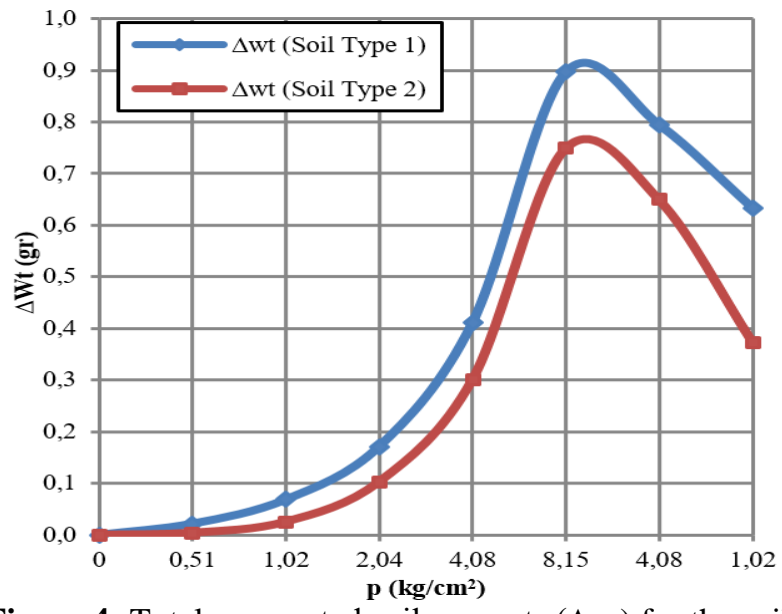

Figure 4: Total compacted soil amounts $\left(\Delta \mathrm{w}_{t}\right)$ for the soil type 1 and soil type 2 samples

The values for the total compacted soil amounts were obtained by Equation 6 below[4]:

$$
\Delta W_{t}=A \Delta z \Delta \gamma_{k}
$$

where, $\mathrm{A}$ is cross sectional area, $\mathrm{z}$ is deformational height and $\gamma_{\mathrm{k}}$ is dry unit weight[4].

The equations for obtaining the values for dispersed $\left(\Delta W_{s}\right)$ and total $\left(\Delta \mathrm{W}_{\mathrm{t}}\right)$ soil amounts which are given as Equation 5 and Equation 6, respectively were also derived from the solutions of the differential equation given in equation 1 [2], [4].

If the correlation given in Figure 4 is observed, it is seen that all of the values for the Soil Type 1 samples are higher than that for the Soil Type 2 samples.

This relation is also the cause of the effect of dry unit weight variation percentages which is higher for the Soil Type 1 samples.

\section{Conclusion}

This study presents information on the subject of hydrodynamic dispersion and the effect of dry unit weight variations on the consolidation of clayey soils.

The equations for finding variations in effective stresses, diffusivity coefficients, dispersive flux, dispersive and total compacted soil amounts and if deserved time rates of settlements, time rates of pore water and time rates of compression of soil skeletoncan be obtained as a result of solving the differential equation given as Equation 1.

The aforementioned equations were shown to give results that are in a very close agreement to the experimental counterparts.

On the other hand, diffusive and dispersive characteristic of a specific region in Mersin Turkey was investigated in this study and the effects of dry unit weight were discussed in order to clarify hydrodynamic dispersion in a consolidation phenomenon.

\section{References}

[1] M. Battaglio, N.Bellomo, I.Bonzani and R.Lancellotta,"Non-Linear Consolidation Models of Clay Which Change Type," Int. J. of Non-Linear Mechanics, 30, 493-500, 2003. (journal style)

[2] M.A.Tekinsoy, "Theoretical Soil Mechanics, Soil Behavior in $\mathrm{K}_{0}$ Condition," DaisyScience International Publishing House, 2013. (book style)

[3] D.R.Nielsen, R.D. Jackson, J.W. Cary, D.D. Evans, "Soil Water. American Society of Agronomy," Soil Science Society of America, pp. 31-39, 1972. (journal style)

[4] B.Mahmutluoğlu,

"HidrodinamikDispersiyonunKonsolidasyona Olan Etkisi," PhD Thesis, Çukurova University Institution of Natural and Applied Sciences, Adana, 2016. (book style) 


\section{International Journal of Science and Research (IJSR) \\ ISSN (Online): 2319-7064}

Index Copernicus Value (2015): 78.96 | Impact Factor (2015): 6.391

[5] B. Mahmutluoğlu, M.A. Tekinsoy and B.Bagriacik, "Grain diffusion and dispersion of clayey soils in a consolidation phenomenon," International Energy and Engineering Conference, pp. 373-381, 2016. (journal style)

\section{Author Profile}

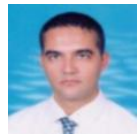

BarışMahmutluoğlu entered Gaziantep University Faculty of Engineering and Architecture Department of Civil Engineering in 1995. In 1999, he graduated from the Faculty of Engineering and Architecture and the Department of Civil Engineering. In 2003, he completed his master's degree in Civil Engineering Department of Gaziantep University Institute of Science and was awarded the title of "High Engineer". In 2014, he completed his Ph.D. in Civil Engineering Department of Cukurova University Institute of Science and was awarded the title of "Doctor". He is still working as a physician teaching staff at Mersin University Department of Construction Technology. There are many publications, notifications, awards and citations.

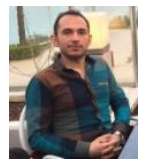

BakiBagriacik entered Cukurova University Faculty of Engineering and Architecture Department of Civil Engineering in 2004. In 2008, he graduated from the Faculty of Engineering and Architecture and the Department of Civil Engineering as the first. 30th anniversary of the establishment of the Faculty of Engineering and Architecture held at Cukurova University in celebration of the project and a final assignment in the competition won the first Civil Engineering and Engineering Faculty of Architecture eligible to receive awards as the latter. In addition, it is entitled to receive certificates and awards from different institutions and organizations. In 2010, he completed his master's degree in Civil Engineering Department of Cukurova University Institute of Science and was awarded the title of "High Engineer" and received scholarship support by TUBITAK during his master's degree. In 2015, he completed his Ph.D. in Civil Engineering Department of Cukurova University Institute of Science and was awarded the title of "Doctor" and received scholarship support by TUBITAK during his $\mathrm{Ph} . \mathrm{D}$. He is still working as a physician teaching staff at Cukurova University Faculty of Engineering and Architecture Department of Civil Engineering. There are many publications, notifications, awards and citations in his field of specialization in various national and international journals and symposia.

Volume 6 Issue 7, July 2017 www.ijsr.net 